(C) 2017, Elsevier. Licensed under the Creative Commons Attribution-NonCommercial-NoDerivatives 4.0 International

http://creativecommons.org/licenses/by-nc-nd/4.0/

\title{
CATALYTIC HYDRODEOXYGENATION OF m-CRESOL OVER Ni 2 P/HIERARCHICAL ZSM-5
}

Antonio Berenguer ${ }^{1}$, James A. Bennett ${ }^{2}$, James Hunns,${ }^{2}$ Inés Moreno ${ }^{1,3}$, Juan M. Coronado ${ }^{1}$, Adam F. Lee, ${ }^{2}$

$$
\text { Patricia Pizarro }{ }^{1,3}, \text { Karen Wilson }{ }^{2 *} \text {, David P. Serrano }{ }^{1,3^{*}}
$$

${ }^{1}$ IMDEA Energy Institute, Avda. Ramón de la Sagra 3, Móstoles, Madrid, Spain.

${ }^{2}$ European Bioenergy Research Institute, Aston University, Aston Triangle, Birmingham, United Kingdom.

${ }^{3}$ Chemical and Environmental Engineering Group, ESCET, Rey Juan Carlos University, c/ Tulipán s/n,

$$
\text { Móstoles, Madrid, Spain. }
$$

\section{Corresponding authors*:}

Tel.: +34 917371120, E-mail address: david.serrano@imdea.org (David P. Serrano). Thermochemical Processes Unit, IMDEA Energy Institute, 28935, Móstoles, Madrid, Spain.

Tel.: +44 (0)121 2044036. E-mail address: k.wilson@aston.ac.uk (Karen Wilson). European Bioenergy Research Institute, Aston University, Birmingham, B4 7ET, UK.

\begin{abstract}
Bifunctional catalysts comprising $\mathrm{Ni}_{2} \mathrm{P}$ supported over a hierarchical ZSM-5 zeolite (h-ZSM-5) were synthesized and applied to the hydrodeoxygenation (HDO) of m-cresol, a model pyrolysis bio-oil compound. Surface and bulk characterization of $\mathrm{Ni}_{2} \mathrm{P} / \mathrm{h}-\mathrm{ZSM}-5$ catalysts by XRD, TEM, DRIFTS, TPR, porosimetry and propylamine temperature-programmed desorption reveal that $\mathrm{Ni}_{2} \mathrm{P}$ incorporation modifies the zeolite textural properties through pore blockage of the mesopores by phosphide nanoparticles, but has negligible impact of the micropore network. $\mathrm{Ni}_{2} \mathrm{P}$ nanoparticles introduce new, strong Lewis acid sites, whose density is proport ional to the $\mathrm{Ni}_{2} \mathrm{P}$ loading, accompanied by new Brönsted acid sites attributed to the presence of P-OH moieties. $\mathrm{Ni}_{2} \mathrm{P} / \mathrm{h}-\mathrm{ZSM}-5$ is ultraselective (> $97 \%$ ) for m-cresol HDO to methylcyclohexane, significantly outperforming a reference $\mathrm{Ni}_{2} \mathrm{P} / \mathrm{SiO}_{2}$ catalyst and highlighting the synergy between metal phosphide and solid acid support. m-Cresol conversion was proportional to $\mathrm{Ni}_{2} \mathrm{P}$ loading reaching 80 and $91 \%$ for 5 and $10 \mathrm{wt} \%$ Ni respectively. Turnover frequencies for $\mathrm{m}$-cresol $\mathrm{HDO}$ are a strong function of $\mathrm{Ni}_{2} \mathrm{P}$ dispersion, evidencing a structure sensitivity, with optimum activity observed for $4 \mathrm{~nm}$ particles.
\end{abstract}

Keywords: Hydrodeoxygenation; m-cresol; nickel phosphide; hierarchical ZSM-5 


\section{Introduction}

Extensive efforts are being made to develop renewable energy sources to meet growing energy demand and environmental and sociopolitical concerns arising from a current heavy global dependence on fossil fuels. [1-3] Lignocellulosic biomass is considered a sustainable and abundant feedstock which can be effectively converted into liquid fuels via fast pyrolysis technologies. [44-5] Unfortunately, the liquid fraction obtained from biomass fast pyrolysis, known as pyrolysis bio-oil, is unsuitable for direct use as a transportation fuel (or as a fuel additive) because of its low heating value and high corrosiveness caused by the presence of significant oxygenated compounds (ketones, aldehydes, organic acids, furans, phenolic derivatives and lignin-derived oligomers). Such organic compounds are highly reactive, promoting the formation of ethers, acetals, hemiacetals and heavier organics through condensation reactions, resulting in low bio-oil stability. Accordingly, pyrolysis bio-oil requires upgrading to obtain a liquid fuel with properties similar to those derived from fossil resources. $[1,2,6]$

Catalytic hydrodeoxygenation (HDO) is an effective bio-oil upgrading strategy which involves the stabilization and selective removal of oxygen from the raw bio-oil using moderate temperatures and mediumhigh hydrogen pressures in the presence of heterogeneous catalysts. Hydrodeoxygenation normally occurs via hydrogenolysis of $\mathrm{C}-\mathrm{O}$ bonds with the consequent elimination of oxygen as water. Decarboxylation/decarbonylation, hydrogenation-hydrocracking of large molecules, and hydrogenation reactions of unsaturated molecules, can also occur during HDO. [7-9]

Due to the complex composition of pyrolysis bio-oils, and the difficulty of deconvoluting the resultant possible reactions during bio-oil HDO, catalyst development studies typically employ model compounds to obtain fundamental mechanistic insight into bio-oil upgrading. [10] Lignin derived phenolic compounds (phenols, guaiacols, syringols, etc.) are one of the most abundant families in pyrolysis bio-oils, and extensively contribute to bio-oil instability and aging, being the main source of coke deposition over catalyst surfaces. Hydrogenation, deoxygenation and ring-opening of phenolic derivatives thus represent critical challenges to commercial bio-oil upgrading. [9-13]

HDO catalysts are usually classified in two categories: conventional hydrotreating catalysts, such as sulfided $\mathrm{CoMo}$ and $\mathrm{NiMo} / \gamma-\mathrm{Al}_{2} \mathrm{O}_{3}$, and unconventional catalysts including supported noble and transition metals. [14-16] Noble metal catalysts, such as $\mathrm{Pd}, \mathrm{Ru}, \mathrm{Pt}$ and $\mathrm{Rh}$ deposited on active carbon, $\mathrm{Al}_{2} \mathrm{O}_{3}$ and $\mathrm{ZrO}_{2}$, 
have been extensively used for HDO of phenolic model compounds to yield aromatic hydrocarbons and saturated cyclic compounds. Compared to conventional sulfided catalysts, noble metal catalysts are more active and do not require the addition of sulfur containing compounds to prevent catalyst deactivation. Nevertheless, the high cost of such noble metals limits their industrial application. [17-20] Alternative transition metals, notably $\mathrm{Ni}$ and $\mathrm{Ni} / \mathrm{Cu}$ alloys, have been also explored for HDO of model compounds and raw bio-oils [1, 2123]. However, Ni catalysts promote secondary reactions such as C-C bond hydrogenolysis, methanation and decarbonylation, resulting in carbon loss and a high hydrogen consumption. In contrast, transition metal phosphides appear promising catalysts for pyrolysis bio-oil HDO for various phenolics including phenol, guaiacol, p-cresol and anisole [24-29]: $\mathrm{Ni}_{2} \mathrm{P}$ exhibits superior $\mathrm{HDO}$ performance to $\mathrm{Co}_{2} \mathrm{P}, \mathrm{Fe}_{2} \mathrm{P}$, WP and MoP. This enhanced performance is attributed to the higher d-electron density of $\mathrm{Ni}_{2} \mathrm{P}$ phase, and a combination of structural and electronic influences of phosphorus atoms on the transition metal sites, which favors oxygenate adsorption and $\mathrm{C}-\mathrm{O}$ bond cleavage. [24, 27-29] According to the literature, the formation of the $\mathrm{Ni}_{2} \mathrm{P}$ phase requires a high temperature during the reduction treatment and is favored by the presence of phosphorus excess during the support impregnation. In this sense, several studies established that optimal molar Ni/P ratio is ranged between 1-1.4. Higher ratios promote the formation of less active nickel phosphide phases $\left(\mathrm{Ni}_{12} \mathrm{P}_{5}\right.$ and $\left.\mathrm{Ni}_{3} \mathrm{P}\right)$ while lower ratios yield to higher $\mathrm{Ni}_{2} \mathrm{P}$ particle size, leading to a lower catalytic activity as a consequence of the reduced number of available centers for hydrogenation. [30-33]

$\mathrm{Ni}_{2} \mathrm{P}$ is often supported over neutral solids including $\mathrm{SiO}_{2}, \mathrm{SBA}-15, \mathrm{MCM}-41$ or carbons. [29, 34-36] However, recent investigations have demonstrated acidic supports can enhance the deoxygenation efficiency of metal catalysts. The resulting bifunctional catalysts combine a metal component which activates $\mathrm{C}=\mathrm{C}$ and $\mathrm{C}=\mathrm{O}$ bonds towards hydrogenation, while acid sites promotes dehydration, hydrocracking and isomerization, favoring the complete deoxygenation of refractory phenolic derivatives. $[7,26,31]$ Zeolites are of especial interest as the acid component of HDO bifunctional systems due to their tunable acidity and stability under severe reaction conditions. Zeolites including ZSM-5, Beta, MCM-22 and Y have been recently employed as supports for noble and transition metal active phases $[\mathbf{1 0 , 2 1 , 3 8 - 4 0 ] , ~ h o w e v e r ~ t h e r e ~ a r e ~ n o ~ s y s t e m a t i c ~ s t u d i e s ~ o n ~}$ their promotion by metal phosphides for HDO.

Hierarchical zeolites are a novel class of materials possessing secondary mesopores of 2-50 nm diameter in addition to the intrinsic zeolitic micropore framework. This bimodal pore architecture may be advantageous 
when employing hierarchical zeolites as supports for catalytically active metal nanoparticles, wherein mesopores may enhance the active phase dispersion. Such hierarchical materials also present less diffusional and steric constraints than conventional microporous zeolites, which is especially important for the transformation of large bio-molecules. Hierarchical ZSM-5 and Y zeolites functionalized with Pt and Ni are promising bifunctional catalysts. [41-43]

Here we investigate possible synergies between metallic $\mathrm{Ni}_{2} \mathrm{P}$ nanoparticles and a hierarchical ZSM-5 zeolite for m-cresol HDO (as a model for the most abundant and refractory compounds in pyrolysis bio-oils) as a function of phosphide loading. Physicochemical and catalytic properties of these materials were determined and their performance compared with those of $\mathrm{Ni}_{2} \mathrm{P}$ over a non-acidic $\mathrm{SiO}_{2}$ support.

\section{Experimental}

\subsection{Materials preparation}

\subsubsection{Synthesis of $h-Z S M-5$}

Hierarchical ZSM-5 (h-ZSM-5) was prepared following a literature procedure based on the crystallization of silanized protozeolitic units. [44] Typically, a clear gel with a molar composition of $1 \mathrm{Al}_{2} \mathrm{O}_{3}$ : $80 \mathrm{SiO}_{2}: 14.4$ TPAOH: $2015 \mathrm{H}_{2} \mathrm{O}$ was prepared from tetraethoxysilane (TEOS, $98 \mathrm{wt} \%$, Aldrich) and aluminium isopropoxide (AIP, $98 \mathrm{wt} \%$, Aldrich) as silica and aluminum precursors and tetrapropylammonium hydroxide (TPAOH, $40 \mathrm{wt} \%$, Alfa) as template. This solution was pre-crystallized under reflux and stirring at $90{ }^{\circ} \mathrm{C}$ for 20 h. Subsequently, the resulting zeolitic seeds were functionalized by reaction with a silanization agent, phenylaminopropyltrimethoxysilane (PHAPTMS, $95 \mathrm{wt} \%$, Aldrich), at $90{ }^{\circ} \mathrm{C}$ for $6 \mathrm{~h}$. The organosilane was added in a proportion of $8 \mathrm{~mol} \%$ relative to the initial silica content of the gel. Finally, the resulting solution was crystallized in a Teflon-lined stainless-steel autoclave at $170^{\circ} \mathrm{C}$ for 7 days. The solid product obtained was separated by centrifugation, washed several times with distilled water, dried overnight at $110{ }^{\circ} \mathrm{C}$ and calcined at $550{ }^{\circ} \mathrm{C}$ for $5 \mathrm{~h}$ under static air.

\subsubsection{Metal phosphide incorporation}

Supported nickel phosphide catalysts were prepared by a temperature-programmed reduction (TPR) method. [45] The zeolite was first impregnated with an aqueous solution of nickel and phosphorus precursors, 
$\left(\mathrm{NH}_{4}\right)_{2} \mathrm{HPO}_{4}$ (Aldrich) and $\mathrm{Ni}\left(\mathrm{NO}_{3}\right)_{2} \cdot 6 \mathrm{H}_{2} \mathrm{O}$ (Aldrich) using an equimolar $\mathrm{Ni} P \mathrm{P}$ ratio, and nominal nickel loadings of 2.5, 5 and $10 \mathrm{wt} \%$. The supported materials were dried overnight at room temperature and subsequently at $120{ }^{\circ} \mathrm{C}$ for $24 \mathrm{~h}$. Dried samples were then calcined at $500{ }^{\circ} \mathrm{C}$ for $4 \mathrm{~h}$. Resulting phosphate catalysts were pelletized, crushed and sieved to 40-60 mesh (250-180 $\mu \mathrm{m})$, prior to reduction under flowing $\mathrm{H}_{2}$ ( $80 \mathrm{ml} / \mathrm{min}$ ) in a tubular furnace: samples were heated from room temperature to $350{ }^{\circ} \mathrm{C}$ at $5{ }^{\circ} \mathrm{C} / \mathrm{min}$; from 350 ${ }^{\circ} \mathrm{C}$ to $650{ }^{\circ} \mathrm{C}$ at $1{ }^{\circ} \mathrm{C} / \mathrm{min}$ and then held isothermally for $3 \mathrm{~h}$. Immediately after the last reduction step samples were passivated by the progressive introduction of synthetic air during cooling to room temperature. Passivation was used to create an oxide layer to inhibit deeper sample oxidation on air exposure during transfer to the catalytic reactor. $\mathrm{Ni}_{2} \mathrm{P}$ supported on a commercial $\mathrm{SiO}_{2}$ sample (Aldrich, fumed powder, 0.2-0.3 $\mu \mathrm{m}$ average particle size, surface area $200 \mathrm{~m}^{2} / \mathrm{g} \pm 25 \mathrm{~m}^{2} / \mathrm{g}$ ) was similarly prepared using with a nominal $10 \mathrm{wt} \%$ nickel loading.

\subsection{Catalyst characterization}

X-ray diffraction (XRD) patterns of catalysts were recorded with a Philips PW 3040/00 X'Pert MPD/MRD diffractometer using $\mathrm{Cu} \mathrm{K}_{\alpha}$ radiation operated at $45 \mathrm{kV}$ and $40 \mathrm{~mA}$. Crystalline phases were indexed through comparison with the JCPDS (Joint Committee on Powder Diffraction Standards) database.

Argon adsorption-desorption isotherms were measured at $87 \mathrm{~K}$ using a Quantrachrome Autosorb-1 analyzer, following degassing at $573 \mathrm{~K}$ for $5 \mathrm{~h}$ prior to analysis. Total surface areas were calculated according to the BET method, while pore size distributions, and surface areas and pore volume associated with the microand mesopore networks calculated using the NL-DFT model assuming cylindrical pore geometry.

Transmission electron microscopy (TEM) images were recorded in a PHILIPS TECHNAI 20 electron microscope operating at $200 \mathrm{kV}$ and $2.7 \AA$ resolutions. Samples were dispersed in acetone and dropped on a carbon-coated copper grid. Nickel, aluminum and phosphorus contents were determined on a Varian VISTAMPX Inductively Coupled Plasma-Optical Emission Spectrometer (ICP-OES).

Acid strength was determined by propylamine thermogravimetric analysis coupled with mass spectrometry (TGA-MS). Prior to analyses, samples were wet-impregnated with propylamine and then dried overnight under vacuum at $60{ }^{\circ} \mathrm{C}$. Thermal desorption was performed on a Mettler Toledo TGA/DSC 2 StarSystem between 40 and $800{ }^{\circ} \mathrm{C}$ under a He flow of $20 \mathrm{~mL} / \mathrm{min}$, using a ramp rate of $10{ }^{\circ} \mathrm{C} / \mathrm{min}$ and gas 
detection through a Pfeiffer Vacuum, ThermoStar MS. Chemisorbed propylamine decomposes into propene and ammonia over acid sites.

Brönsted/Lewis acid character was studied by means of Diffuse Reflectance Infrared Fourier Transform Spectroscopy (DRIFTS) using pyridine as probe molecule. Ex situ pyridine adsorption was performed by saturation of diluted samples ( $5 \mathrm{wt} \%$ in $\mathrm{KBr}$ ). Excess physisorbed pyridine was removed under vacuum at 60 ${ }^{\circ} \mathrm{C}$ prior to spectral acquisition on a Nicolet Avatar spectrometer at $50{ }^{\circ} \mathrm{C}$ in a Harrick environmental cell.

Metal dispersion was determined by temperature programmed desorption of $\mathrm{H}_{2}\left(\mathrm{H}_{2}-\mathrm{TPD}\right)$ employing a Micromeritics AUTOCHEM 2910 apparatus on $100 \mathrm{mg}$ of sample loaded in a quartz U-tube reactor. Sample were reduced at $650{ }^{\circ} \mathrm{C}$ under flowing $10 \mathrm{vol} \% \mathrm{H}_{2}$ in $\mathrm{Ar}$ (with a stream of $50 \mathrm{ml} / \mathrm{min}$ ) for $30 \mathrm{~min}$., then cooled to $60{ }^{\circ} \mathrm{C}$ and held for $60 \mathrm{~min}$. Subsequently, the $\mathrm{H}_{2} / \mathrm{Ar}$ mixture was changed to $50 \mathrm{ml} / \mathrm{min}$ of $\mathrm{Ar}$ and held for 30 $\min$. Chemisorbed hydrogen was measured from its subsequent desorption on heating from 60 to $600{ }^{\circ} \mathrm{C}$ at 10 ${ }^{\circ} \mathrm{C} / \mathrm{min}$. Nickel dispersions (\% D) were calculated from the volume of chemisorbed $\mathrm{H}_{2}[46]$ assuming atomic hydrogen only binds to nickel surface atoms with a H:Ni stoichiometry of 1.

\subsection{Catalytic experiments}

The HDO catalytic activity of the metal phosphide supported materials was evaluated in a $50 \mathrm{~mL}$ stainless steel Parr autoclave using m-cresol as model compound. Initially, $50 \mathrm{ml}$ of a solution containing 1.5 wt $\%$ of m-cresol (98 wt\%, Aldrich) in dodecane (99 wt\%, Aldrich), together with $100 \mathrm{mg}$ of catalyst, were loaded into the reactor. Prior to the HDO catalytic tests the sealed autoclave was purged by flowing pure $\mathrm{N}_{2}$ at room temperature. The reactor was then heated to the reaction temperature $\left(200^{\circ} \mathrm{C}\right)$ under vigorous stirring $(800$ $\mathrm{rpm}$ ) and once at temperature pressurized with 25 bar pure $\mathrm{H}_{2}$. Reactant and liquid products were analyzed offline by gas chromatography (Varian 3800 GC) equipped with a FID detector and VF-5ms column (30 m x 0.25 $\mathrm{mm} \times 0.25 \mu \mathrm{m})$.

Catalytic performance was evaluated by several parameters: m-cresol conversion ( $\left.\mathrm{X}_{\mathrm{CRE}}\right)$, selectivity towards $i$ product $\left(\mathrm{S}_{\mathrm{i}}\right)$, deoxygenation degree (HDO), dearomatization degree (HDA) and TOF (Turnover Frequency) according to the following equations:

(1) $\quad \mathrm{X}_{\mathrm{CRE}}(\%)=\frac{\mathrm{n}_{\mathrm{CRE}}^{0}-\mathrm{n}_{\mathrm{CRE}}^{\mathrm{F}}}{\mathrm{n}_{\mathrm{CRE}}^{0}} \times 100$ 
(2) $\quad \mathrm{S}_{\mathrm{i}}=\frac{\mathrm{n}_{\mathrm{i}}}{\mathrm{n}_{\mathrm{CRE}}^{0}-\mathrm{n}_{\mathrm{CRE}}^{\mathrm{F}}} \times 100$

$$
\begin{aligned}
& \text { (3) } \operatorname{HDO}(\%)=\left(1-\frac{\sum_{\mathrm{i}} \mathrm{n}_{\mathrm{i}} \mathrm{O}_{\mathrm{i}}}{\mathrm{n}_{\mathrm{CRE}}^{0} \times \mathrm{X}_{\mathrm{CRE}}}\right) \times 100 \\
& \text { (4) } \operatorname{HDA}(\%)=\left(1-\frac{\sum_{\mathrm{i}} \mathrm{n}_{\mathrm{i}} \mathrm{A}_{\mathrm{i}}}{\mathrm{n}_{\mathrm{CRE}}^{0} \times \mathrm{X}_{\mathrm{CRE}}}\right) \times 100 \\
& \text { (5) } \mathrm{TOF}\left(\mathrm{min}^{-1}\right)=\frac{V_{C R E}}{W \times \mathrm{M}}
\end{aligned}
$$

Where $n^{0}{ }_{C R E}$ and $n^{\mathrm{F}}{ }_{\text {CRE }}$ represent the initial and final moles of $m$-cresol, respectively; $n_{i}$ the moles of product $\mathrm{i} ; \mathrm{O}_{\mathrm{i}}$ the number of oxygen atoms in product $\mathrm{I} ; \mathrm{A}_{\mathrm{i}}$ the number of aromatic rings in product $i ; \mathrm{V}_{\mathrm{CRE}}$ the rate of conversion of $\mathrm{m}$-cresol; $\mathrm{W}$ the mass $(\mathrm{g})$ of active phase; and $\mathrm{M}$ the molecular weight $\left(\mathrm{mmol} \cdot \mathrm{g}^{-1}\right)$ of active phase.

\section{Results and discussion}

\subsection{Catalyst characterization}

Catalyst were reduced at $650{ }^{\circ} \mathrm{C}$ and subsequently passivated under air in order to preserve a metal phosphide phase during under atmospheric exposure. Fig. 1 shows powder XRD patterns of Ni $2 \mathrm{P} / \mathrm{h}-\mathrm{ZSM}-5$ samples and the parent zeolite. All materials exhibited high crystallinity characteristic of the parent MFI zeolite structure, with the intensity and position of the MFI reflections (and hence zeolite crystallinity) unaffected by the reduction pretreatment. Additional peaks at $2 \theta=40.7,44.6$ and $47.4^{\circ}$ were assigned to (111), (201) and (210) reflections of $\mathrm{Ni}_{2} \mathrm{P}$ (PDF code: 03-065-1989), whose formation was promoted by the excess of $\mathrm{P}$ used during the support impregnation $\left([\mathrm{Me} / \mathrm{P}]_{\mathrm{MOL}} \sim 1.0\right)$ and the high reduction temperature during synthesis. [3033] No additional peaks due to metallic Ni or ordered phosphate phases were observed, consistent with the complete reduction of nickel and phosphorus precursors. $\mathrm{Ni}_{2} \mathrm{P}$ reflections broadened and weakened with decreasing $\mathrm{Ni}$ loading, being almost undetectable for the $2.5 \mathrm{Ni}_{2} \mathrm{P} / \mathrm{h}-\mathrm{ZSM}-5$ sample, indicating a decrease in nickel phosphide nanoparticle size, in agreement with particle size distributions visualized by TEM (Fig. 2). TEM images of $10 \mathrm{Ni}_{2} \mathrm{P} / \mathrm{h}-\mathrm{ZSM}-5$ reveal a broad distribution of phosphide nanoparticles with a mean particle size of $15 \mathrm{~nm}$ (although some $>50 \mathrm{~nm}$ particles were also present). $\mathrm{Ni}_{2} \mathrm{P}$ nanoparticles were more 
homogeneously dispersed over the zeolite for the $5 \mathrm{Ni}_{2} \mathrm{P} / \mathrm{h}-\mathrm{ZSM}-5$ sample, which exhibited a smaller mean particle size around $7 \mathrm{~nm}$, and the $2.5 \mathrm{Ni}_{2} \mathrm{P} / \mathrm{h}-\mathrm{ZSM}-5$ sample for which the mean particle size was $\sim 4 \mathrm{~nm}$.

Fig. 3 shows Ar adsorption-desorption isotherms and corresponding pore size distributions for the supported phosphides and parent zeolite (subjected to an identical reductive and passivation pretreatment). All samples exhibited an intermediate shape between type I and IV isotherms (according to the IUPAC classification) due to the co-existence of micro- and mesopores: the strong adsorption observed at low relative pressures $\left(\mathrm{P} / \mathrm{P}_{0}<0.2\right)$ is characteristic of microporous materials, while the continuous Ar uptake at intermediate relative pressures is typical of mesoporous solids. The presence of a bimodal pore structure was confirmed from NL-DFT calculations which reveal a narrow and well-defined peak at $5 \AA$, attributed to the zeolitic micropores of the MFI crystalline structure, in addition to a broad pore distribution spanning 20-60 $\AA$ arising from the mesopore network.

For all Ni loadings, a small decrease in Ar adsorption was observed following metal phosphide deposition, although a common isotherm shape was observed. Consequently, the textural properties of the parent support (Table 1) exhibited only small variations upon nickel phosphide incorporation, with the total and mesopore surface areas and volumes around $45 \%$ lower than the parent zeolite, whereas the corresponding micropore areas and volumes showed minimal change. These results indicate that nickel phosphide nanoparticles were largely confined to the mesopores. Phosphide particle sizes for the $2.5 \mathrm{Ni}_{2} \mathrm{P} / \mathrm{h}-\mathrm{ZSM}-5$ sample of $4 \mathrm{~nm}$ lie within the range of the zeolite mesopore diameters $(2-6 \mathrm{~nm})$, and hence it is reasonable to assume that most of these nanoparticles are located within the mesopores. In contrast, TEM shows that the larger phosphide nanoparticles formed for higher Ni loadings (>7 nm) are unlikely to reside within the mesopores, and a significant proportion are expected to distribute over the outer surface of the zeolite, and hence not block mesopores.

The chemical composition of both catalysts and raw support were determined by ICP-OES analyses (Table 1). In all cases the actual Ni:P molar ratios were between 1.00 and 1.19 , close to the nominal ratio employed during impregnation. XRD indicates that despite the equimolar ratio of $\mathrm{Ni}$ and $\mathrm{P}$ precursors, only a crystalline metal-rich $\mathrm{Ni}_{2} \mathrm{P}$ phase formed during thermal processing, and we propose that this residual phosphorus is be present as a highly dispersed (molecular) phosphite or phosphate species. 
Fig. 4 shows DRIFT spectra of the $\mathrm{Ni}_{2} \mathrm{P} / \mathrm{h}-\mathrm{ZSM}-5$ and parent zeolite following pyridine chemisorption. Absorption features at 1447, 1547, 1490 and $1638 \mathrm{~cm}^{-1}$ observed for the parent zeolite are assigned to pyridine adsorbed at Lewis acid sites (PyL, $1447 \mathrm{~cm}^{-1}$ ) arising from partially coordinated $\mathrm{Al}$ atoms and extra-framework aluminum in the form of $\mathrm{AlO}^{+}, \mathrm{Al}(\mathrm{OH})^{2+}, \mathrm{Al}(\mathrm{OH})_{3}, \mathrm{Al}(\mathrm{OH})_{2}{ }^{+}$species. The $1490 \mathrm{~cm}^{-1}$ band is attributed to pyridine molecules adsorbed over Brönsted and Lewis acid sites, while that at $1596 \mathrm{~cm}^{-1}$ corresponds to pyridine hydrogen-bonded to weak free silanol groups. [47] The intensity of the latter band progressively decreased with $\mathrm{Ni}$ loading, presumably due to surface and pore blocking by the metal phosphide nanoparticles. $\mathrm{Ni} 2 \mathrm{P} / \mathrm{h}-\mathrm{ZSM}-5$ samples also exhibited a new absorption band appeared at $1608 \mathrm{~cm}^{-1}$ whose intensity increased with Ni loading, and is attributed to the genesis of new Lewis acid sites arising from $\mathrm{Ni} \rightarrow \mathrm{P}$ electron transfer and the formation of $\mathrm{Ni}^{8+}$ species. The blue shift of this new Lewis acid band relative to the parent h-ZSM-5 $\left(1447 \mathrm{~cm}^{-1}\right.$ and 1596 $\mathrm{cm}^{-1}$ ) indicates that the former possesses stronger acidity. [49, 49] Bands at 1547 and $1638 \mathrm{~cm}^{-1}$ are commonly attributed to pyridinium ions $\left(\mathrm{PyH}^{+}\right)$coordinated to Brönsted acid sites; these are broadened and red shifted in the $\mathrm{Ni}_{2} \mathrm{P} / \mathrm{h}$-ZSM-5 samples, suggesting weaker Brönsted acidity following nickel phosphide deposition, which may again reflect blocking of Brönsted sites in the parent zeolites. However, suppression of the intrinsic Brönsted acidity of the zeolite may be partially compensated by the presence of molecular P-OH species as noted above.

Acid properties were quantified by TGA-MS after following propylamine chemisorption. The latter is a weak base that reacts with accessible acid sites to evolve propene and ammonia during thermal processing; the desorption temperature of reactively-formed propene is inversely proportional to acid strength. Fig. $\mathbf{5}$ displays propene desorption profiles from propylamine TGA-MS for $\mathrm{Ni}_{2} \mathrm{P} / \mathrm{h}-\mathrm{ZSM}-5$ and the parent h-ZSM-5 zeolite, alongside that of $\mathrm{Ni}_{2} \mathrm{P} / \mathrm{SiO}_{2}$ reference material. The parent zeolite exhibited two propene desorptions centered at 412 and $475^{\circ} \mathrm{C}$, with the former assigned to the Lewis acid sites and the latter to acidic bridging Si$\mathrm{OH}-\mathrm{Al}$ groups (typical Brönsted acid sites in the zeolite). $\left[\mathbf{5 0 , 5 1 ]}\right.$ The higher intensity of the $412{ }^{\circ} \mathrm{C}$ desorption for the h-ZSM-5 evidences dominant Lewis acidity associated with the secondary porosity. [47] $\mathrm{The}^{\mathrm{Ni}} \mathrm{P}_{2} / \mathrm{SiO}_{2}$ sample exhibited only a broad desorption around $375^{\circ} \mathrm{C}$, which, owing to the lack of acidity of the $\mathrm{SiO}_{2}$ support, can be only assigned to Lewis acid sites generated by $\mathrm{Ni}_{2} \mathrm{P}$ species. A weak higher temperature shoulder also hints at the existence of a small proportion of weaker acid sites, probably related to P-OH groups. The total acid 
site loading of the silica sample was three times lower than that of the parent zeolitic $(0.34 \mathrm{versus} 0.95 \mathrm{mmol} / \mathrm{g}$, respectively). Propene desorption spectra for $\mathrm{Ni}_{2} \mathrm{P} / \mathrm{h}-\mathrm{ZSM}-5$ materials were intermediate between those of the parent zeolite and $\mathrm{Ni}_{2} \mathrm{P} / \mathrm{SiO}_{2}$, exhibiting desorption peaks at $370{ }^{\circ} \mathrm{C}$ and $454{ }^{\circ} \mathrm{C}$. The first was coincident with that observed from $\mathrm{Ni}_{2} \mathrm{P} / \mathrm{SiO}_{2}$, and is therefore attributed to Lewis acid sites arising from $\mathrm{Ni}_{2} \mathrm{P}$ nanoparticles; the second is attributed to Brönsted acid sites from the parent h-ZSM-5 and surface P-OH groups. The total acid site loadings of all $\mathrm{Ni}_{2} \mathrm{P} / \mathrm{h}-\mathrm{ZSM}-5$ materials were similar to the parent zeolite, indicating that phosphide suppression of the zeolite acidity was quantitatively compensated by the formation of new Lewis and Brönsted sites.

\section{2. $m$-Cresol catalytic activity}

Catalytic HDO of m-cresol was explored over the $\mathrm{Ni}_{2} \mathrm{P} / \mathrm{h}-\mathrm{ZSM}-5$ bifunctional catalysts in a batch reactor at $200{ }^{\circ} \mathrm{C}$ under 25 bar of $\mathrm{H}_{2}$. m-Cresol hydrodeoxygenation is proposed to occur through two competing reaction pathways (Fig. 6). The first involves direct hydrogenation of the aromatic ring (HYD) leading to 3 methylcyclohexanol, which can be sequentially dehydrated and hydrogenated to obtain the fully deoxygenated methylcyclohexane product. The second pathway follows direct C-O bond scission of m-cresol (DDO route) yielding toluene as intermediate product, which is subsequently hydrogenated to methylcyclohexane. [41, 52]

Fig. 7 shows reaction profiles for m-cresol conversion and product formation (selectivity) as a function of $\mathrm{Ni}$ loading over the $\mathrm{Ni}_{2} \mathrm{P} / \mathrm{h}-\mathrm{ZSM}-5$ and $10 \mathrm{Ni}_{2} \mathrm{P} / \mathrm{SiO}_{2}$ reference. In order to evaluate the possible effect of the catalyst acidity on the solvent stability, a blank experiment without m-Cresol was performed using the same reaction conditions, revealing a negligible dodecane hydrocracking. $10 \mathrm{Ni}_{2} \mathrm{P} / \mathrm{SiO}_{2}$ reference exhibited inferior m-cresol conversion compared to the equivalent loading $10 \mathrm{Ni}_{2} \mathrm{P} / \mathrm{h}-\mathrm{ZSM}-5$ (only $50 \%$ versus $91 \%$ ), highlighting the importance of an acidic support. For the $\mathrm{Ni}_{2} \mathrm{P} / \mathrm{h}-\mathrm{ZSM}-5$ materials, $\mathrm{m}-\mathrm{Cresol}$ conversion was proportional to Ni loading, and in all cases m-cresol conversion increased almost linearly with reaction time suggesting minimal catalyst deactivation under our reaction conditions. Corresponding TOFs (normalized per $\mathrm{Ni}_{2} \mathrm{P}$ ) are shown in Fig. 8, together with the $\mathrm{Ni}$ dispersion, and evidence a direct correlation between the $\mathrm{Ni}\left(\mathrm{Ni}_{2} \mathrm{P}\right)$ particle size and activity, indicating HDO is structure sensitive being favored over small $(<7 \mathrm{~nm})$ phosphide particles. The $10 \mathrm{Ni}_{2} \mathrm{P} / \mathrm{SiO}_{2}$ and $\mathrm{Ni}_{2} \mathrm{P} / \mathrm{h}-\mathrm{ZSM}-5$ catalysts also exhibited significant differences in product selectivity (Fig. 7). 
In the initial stage of reaction, $10 \mathrm{Ni}_{2} \mathrm{P} / \mathrm{SiO}_{2}$ only produces 3 -methylcyclohexanol, whose yield subsequently decreases to reach a final selectivity of $60 \%$ after $6 \mathrm{~h}$ reaction as a consequence of secondary methylcyclohexane formation. In contrast, $\mathrm{Ni}_{2} \mathrm{P} / \mathrm{h}-\mathrm{ZSM}-5$ exhibit far more rapid conversion of intermediate methylcyclohexanol, such that the final methylcyclohexane selectivity approaches $100 \%$ after $6 \mathrm{~h}$ independent of Ni loading. The zeolite support is thus critical for complete m-cresol deoxygenation. For the h-ZSM-5 support $\mathrm{Ni}_{2} \mathrm{P}$ catalysts, the rate of methylcyclohexanol removal was also inversely proportional to Ni loading, suggesting that the Brönsted acidity of P-OH groups may also play an important role in methylcyclohexanol dehydration to methylcyclohexane. Since only trace toluene was observed, m-cresol HDO reaction preferentially proceeds through aromatic ring hydrogenation (HYD route) over all $\mathrm{Ni}_{2} \mathrm{P}$ catalysts. Comparison of the product evolution over $\mathrm{Ni}_{2} \mathrm{P} / \mathrm{SiO}_{2}$ and $\mathrm{Ni}_{2} \mathrm{P} / \mathrm{h}-\mathrm{ZSM}-5$ catalysts suggest that the first HYD step (m-cresol conversion to 3methylcyclohexanol) is catalyzed by $\mathrm{Ni}_{2} \mathrm{P}$ active sites alone, while $\mathrm{C}-\mathrm{O}$ bond scission and dehydration are promoted by the zeolite acidity.

Overall m-cresol conversion and HDO and HDA efficiencies are compared in Fig. 9. All the $\mathrm{Ni}_{2} \mathrm{P}$ supported catalysts exhibited high HDA efficiencies, independent of the support, as expected if m-cresol HDO preferentially occurs via the direct hydrogenation route which involves the saturation of aromatic rings catalyzed by the metallic $\mathrm{Ni}_{2} \mathrm{P}$ phase. The $\mathrm{HDO}$ degree exhibited by $\mathrm{Ni}_{2} \mathrm{P} / \mathrm{SiO}_{2}$ was relatively low $(\sim 39 \%)$ compared to the efficiencies of the $\mathrm{Ni}_{2} \mathrm{P} / \mathrm{h}-\mathrm{ZSM}-5$ materials which were all around $100 \%$, again highlighting the synergy between metal nanoparticle and solid acid support components necessary for hydrodeoxygenation.

Finally, the material $5 \mathrm{Ni}_{2} \mathrm{P} / \mathrm{h}-\mathrm{ZSM}-5$ was reutilized in second reaction cycle. In this experiment, the mCresol conversion attained over the spent catalyst was $98 \%$ of the conversion obtained using the fresh material, which denotes the high stability of this catalyst. However, minor changes were detected in terms of product distribution obtained. As it can be appreciated in Fig. 10, the selectivity towards the fully deoxygenated product (methylcyclohexane) is a $10 \%$ lower over the spent catalyst, increasing the selectivity towards methylcyclohexanol. This fact suggests a small lost in the overall HDO activity of this material from the first to the second reaction, probably due to the formation of carbonaceous residues.

\section{Conclusions}


$\mathrm{Ni}_{2} \mathrm{P} / \mathrm{h}-\mathrm{ZSM}-5$ catalysts having Ni loadings spanning 2.5-10 wt $\%$ were synthesis and tested for the hydrodeoxygenation (HDO) of m-cresol. Metal phosphide incorporation has little impact on the crystallinity or microporosity of the hierarchical ZSM-5 zeolite, but modifies both the Lewis and Brönsted acid character of the support, and introduces new strong Lewis acid sites and small amounts of new Brönsted sites possibly arising from $\mathrm{P}-\mathrm{OH}$ moieties. The $\mathrm{Ni}_{2} \mathrm{P}$ dispersion is inversely proportional to $\mathrm{Ni}$ loading, with $2.5 \mathrm{wt} \% \mathrm{Ni}$ favoring uniform $4 \mathrm{~nm}$ particles distributed throughout the mesopore network. Activity for m-cresol HDO is proportional to $\mathrm{Ni}_{2} \mathrm{P}$ content, but exhibits structure sensitivity with small particles offering higher TOFs. $\mathrm{Ni} 2 \mathrm{P} / \mathrm{h}-\mathrm{ZSM}-5$ are ultraselective for the complete hydrodeoxygenation of m-cresol to methylcyclohexane, with reaction proceeding through a direct hydrogenation pathway and methylcyclohexanol intermediate. Brönsted acidity from the zeolite support (and possible P-OH functions) is critical for methylcyclohexanol dehydration, highlighting the importance of bifunctional catalysts possessing both acid and metal active sites for m-cresol HDO.

\section{Acknowledgements}

We thank the Spanish Ministry of Economy and Competitiveness through CATPLASBIO (CTQ2014-60209R) and the regional government of Madrid through RESTOENE-2 (Ref: S2013/MAE-2882), Consejería de Educación de la Comunidad de Madrid), and the EPSRC for financial support (EP/K036548/2 and EP/N009924/1).

\section{References}

1. M. Patel, A. Kumar, Renew. Sustain. Energy Rev. 58 (2016) 1293-1307.

2. P.M. Mortensen, J.D. Grunwaldt, P.A. Jensen, K.G. Knudsen, A.D. Jensen, Appl. Catal. A: Gen. 407 (2011) 1-19.

3. A.V. Bridgwater, D. Meier, D. Radlein, Org. Geochemistry 30 (1999) 1479-1493.

4. G.W. Huber, S. Iborra, A. Corma, Chem. Rev. 106 (2006) 4044-4098.

5. S. Xiu, A. Shahbazi, Renew. Sustain. Energy Rev. 16 (2012) 4406-4414.

6. K. Jacobson, K.C. Maheria, A.K. Dalai, Renew. Sustain. Energy Rev. 23 (2013) 91-106.

7. A.M. Robinson, J.E. Hensley, J.W. Medlin, ACS Catal. 6 (2016) 5026-5043.

8. X. Li, G. Chen, C. Liu, W. Ma, B. Yan, J. Zhang, Renew. Sustain. Energy Rev. 71 (2017) 296-308. 
9. Q. Bu, H. Lei, A.H. Zacher, L. Wang, S. Ren, J. Liang, Y. Wei, Y. Liu, J. Tang, Q. Zhang, R. Ruan, Bioresource Technol. 124 (2012) 470-477.

10. H. Shafaghat, P. S. Rezaei, W. M. A. W. Daud, J. Ind. Eng. Chem 35 (2016) 268-276.

11. C.J. Chen, W. S. Lee, A. Bhan, Appl. Catal. A: Gen. 510 (2016) 42-48.

12. I. Graça, A.M. Carmo, J.M. Lopes, M.F. Ribeiro, Fuel 140 (2015) 484-494.

13. D.A. Ruddy, J.A. Schaidle, J.R. Ferrell, J. Wang, L. Moens, and J.E. Hensley, Green Chem. 16 (2014) $454-490$

14. V.N. Bui, G. Toussaint, D. Laurenti, C. Mirodatos, C. Geantet, Catal. Today 143 (2009) 172-178.

15. A.L. Jongerius, R. Jastrzebski, P.C.A. Bruijnincx, B.M. Weckhuysen, J. Catal. 285 (2012) 315-323.

16. O.I. Senol, T.R. Viljava, A.O.I. Krause, Catal. Today 100 (2005) 331-335.

17. Y. Bie, J. Lehtonen, J. Kanervo, Appl. Catal. A: Gen. 526 (2016) 183-190.

18. J. Wildschut, M. Iqbal, F.H. Mahfud, I. Melian-Cabrera, R.H. Venderbosch, H.J. Heeres, Energy Environ. Sci. 3 (2010) 962-970.

19. S. Oha, H. Hwang, H.S. Choi, J.W. Choi, Fuel 153 (2015) 535-543.

20. A.J. Foster, P.T.M. Do, R. F. Lobo, Top. Catal. 55 (2012) 118-128.

21. X. Zhang, T. Wang, L. Ma, Q. Zhang, T. Jiang, Bioresource Technol. 127 (2013) 306-311.

22. S. Sitthisa, D. Resasco, Catal. Lett. 141 (2011) 784-791.

23. S.A. Khromova, A.A. Smirnov, O.A. Bulavchenko, A.A. Saraev, V.V. Kaichev, S.I. Reshetnikov, V.A. Yakovlev, Kinet. Catal. 55 (2014) 69-78.

24. V.O.O. Goncalves, P. M. de Souza, V. T. da Silva, F. B. Noronh, F. Richard, Appl. Catal. B: Environ. 205 (2017) 357-367.

25. S. T. Oyama, J. Catal. 216 (2016) 343-352.

26. A. Berenguer, T.M. Sankaranarayanan, G. Gómez, I. Moreno, J.M. Coronado, P. Pizarro, D.P. Serrano, Green Chem. 18 (2016) 1938-1951.

27. H.Y. Zhao, D. Li, P. Bui, S.T. Oyama, Appl. Catal. A: Gen. 391 (2011) 305-310.

28. K. Li, R. Wang, J. Chen, Energ. Fuels 25 (2011) 854-863.

29. J.S. Moon, E. G. Kim, Y.K. Lee, J. Catal. 311 (2014) 144-152.

30. S.T. Oyama, X.Wang, Y.K. Lee, K. Bando, F.G. Requejo, Journal of Catalysis 210 (2002) 207-217. 
31. Y. Yang, C. Ochoa-Hernández, P. Pizarro, V.A. de la Peña O’Shea, J.M. Coronado, D.P. Serrano, Fuel 144 (2015) 60-70.

32. J. A. Cecilia, A. Infantes-Molina, E. Rodríguez-Castellón, A. Jiménez-López, Journal of Catalysis, 263 (2009) 4-15.

33. J. Chen, M. Han, S. Zhao, Z. Pan, Z. Zhang, Catal. Sci. Technol. 6 (2016) 3938-3949.

34. T.I. Korányi, Z. Vít, J.B. Nagy, Catal. Today. 130 (2008) 80-85.

35. N. Koike, S. Hosokai, A. Takagaki, S. Nishimura, R. Kikuchi, K.I. Ebitani, Y. Suzuki, S.T. Oyama, J. Catal. 333 (2016) 115-126.

36. Y. Yang, J. Chen, H. Shi, Energ. Fuels 27 (2013) 3400-3409.

37. T. Cordero-Lanzac, R. Palos, J. M. Arandes, P. Castaño, J. Rodríguez-Mirasol, T. Cordero, J. Bilbao, Appl. Catal. B: Environ. 203 (2017) 389-399.

38. Y. Li, C. Zhang, Y. Liu, S. Tang, G. Chen, R. Zhang, X. Tang, Fuel 189 (2017) 23-31.

39. F. Anaya, L. Zhang, Q. Tan, D. E. Resasco, J. Catal. 328 (2015) 173-185.

40. J.S. Yoon, T. Lee, J.W. Choi, D.J. Suh, K. Lee, J.M. Ha, J.Choi, Catal. Today (2017) In Press. (http://doi.org/10.1016/j.cattod.2016.10.033)

41. J.A. Hunns, M. Arroyo, A.F. Lee, J.M. Escola, D. Serrano, K. Wilson, Catal. Sci. Technol. 6 (2016) 25602564.

42. H.W. Lee, B.R. Jun, H. Kim, D.H. Kim, J.K. Jeon, S.H. Park, C.H. Ko, T.W. Kim, Y.K. Park, Energy 81 (2015) 33-40.

43. T. M. Sankaranarayanan, A. Berenguer, C. Ochoa-Hernández, I. Moreno, P. Jana, J. M. Coronado, D. P. Serrano and P. Pizarro, Catal. Today 243 (2015) 163-172.

44. D.P. Serrano, J. Aguado, J.M. Escola, J.M. Rodríguez, Á. Peral, Chem. Mater. 18 (2006) 2462-2464.

45. R. Prins, M. E. Bussell, Catal. Letters. 142 (2012) 1413-1436.

46. R. Wojcieszak, S. Monteverdi, M. Mercy, I. Nowak, M. Ziolek, M.M. Bettahar, Appl. Catal. A: Gen. 268 (2004) 241-253.

47. D.P. Serrano, R.A. García, G. Vicente, M. Linares, D. Procházková, J. Cejka, J. Catal. 279 (2011) 366-

380.48. S.T. Oyama, X. Wang, F. Requejo, T. Sato, Y. Yoshimura, J. Catal.209 (2002) 1-5.

49. D. Li, P. Bui, H.Y. Zhao, S.T. Oyama, T. Dou, Z.H. Shen, J. Catal. 290 (2012)1-12.

50. R.J. Gorte, Catal. Letters. 62 (1999) 1-13. 
51. L.M. Parker, D.M. Bibby, R.H. Meinhold, Zeolites 5 (1985) 384-388.

52. P.T.M. Do, A.J. Foster, J. Chen, R.F. Lobo, Green Chem. 14 (2012) 1388-1397. 
Table 1. Physicochemical properties of the $\mathrm{Ni}_{2} \mathrm{P} / \mathrm{h}-\mathrm{ZSM}-5$ samples and the raw support.

\begin{tabular}{|c|c|c|c|c|c|c|c|}
\hline Sample & $\begin{array}{c}\mathrm{S}_{\mathrm{BET}}^{\mathrm{a}} \\
\left(\mathrm{m}^{2} \mathrm{~g}^{-1}\right)\end{array}$ & $\begin{array}{c}\mathrm{S}_{\mathrm{MES}+\mathrm{EXT}} \mathrm{b} \\
\left(\mathrm{m}^{2} \mathrm{~g}^{-1}\right)\end{array}$ & $\begin{array}{c}\mathrm{S}_{\mathrm{MIC}}^{\mathrm{b}} \\
\left(\mathrm{m}^{2} \mathrm{~g}^{-1}\right)\end{array}$ & $\begin{array}{c}V_{M I C}^{b} \\
\left(\mathrm{~cm}^{3} \mathrm{~g}^{-1}\right)\end{array}$ & $\begin{array}{c}\mathrm{V}_{\mathrm{MES}+\mathrm{EXT}}{ }^{\mathrm{b}} \\
\left(\mathrm{cm}^{3} \mathbf{g}^{-1}\right)\end{array}$ & $\mathrm{Ni}(\% \mathrm{wt})$ & {$[\mathrm{Ni} / \mathbf{P}]_{\mathrm{MOL}}{ }^{\mathrm{c}}$} \\
\hline $\begin{array}{c}\text { h-ZSM-5 } \\
\left(650^{\circ} \mathrm{C} \text { reduced }\right)\end{array}$ & 500 & 226 & 275 & 0.163 & 0.306 & --- & --- \\
\hline $2.5 \mathrm{Ni}_{2} \mathrm{P} / \mathrm{h}-\mathrm{ZSM}-5$ & 407 & 145 & 262 & 0.156 & 0.228 & 2.89 & 1.00 \\
\hline $5 \mathrm{Ni}_{2} \mathrm{P} / \mathrm{h}-\mathrm{ZSM}-5$ & 407 & 146 & 261 & 0.156 & 0.250 & 6.07 & 1.10 \\
\hline $10 \mathrm{Ni}_{2} \mathrm{P} / \mathrm{h}-\mathrm{ZSM}-5$ & 390 & 132 & 259 & 0.154 & 0.246 & 11.13 & 1.19 \\
\hline
\end{tabular}

${ }^{\mathrm{a}}$ BET surface area from Ar adsorption-desorption isotherms $(87 \mathrm{~K})$.

${ }^{\mathrm{b}}$ Calculated by applying the NL-DFT model to Ar adsorption-desorption isotherms (87 K).

${ }^{\mathrm{c}}$ Estimated from ICP-AOS analyses. 


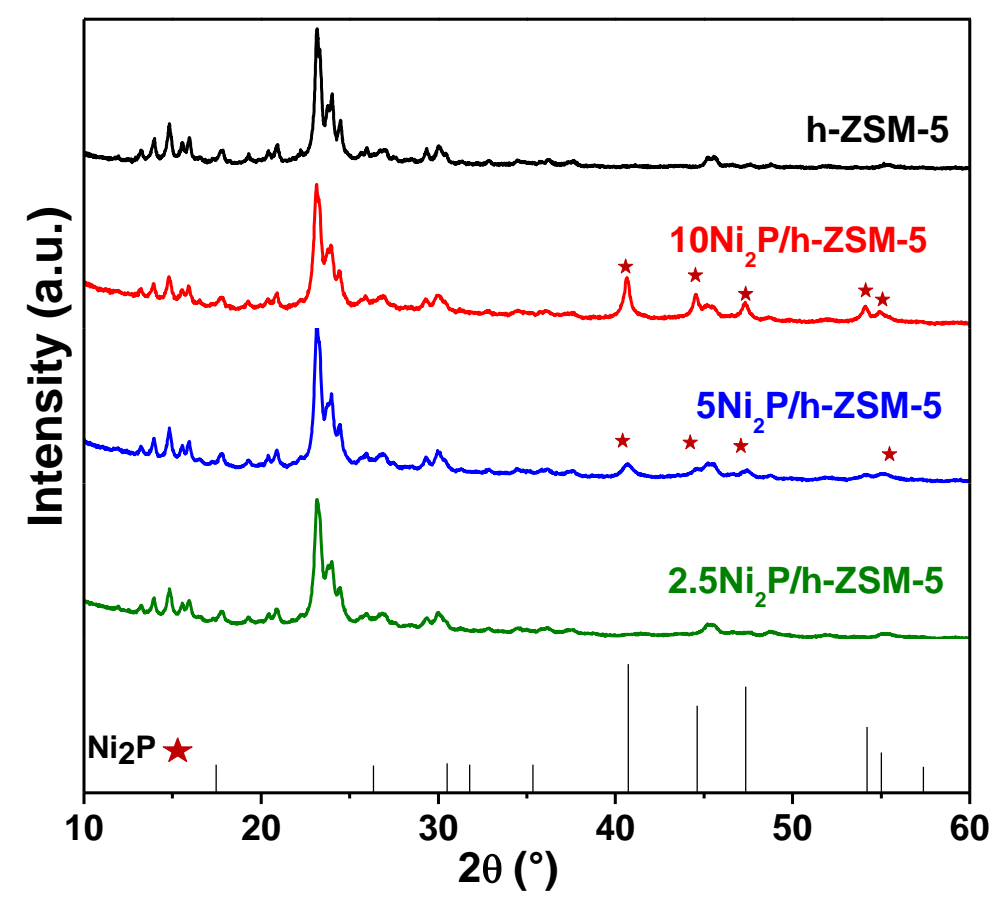

Fig. 1. Wide angle X-ray diffraction patterns of $\mathrm{Ni}_{2} \mathrm{P} / \mathrm{h}-\mathrm{ZSM}-5$ and parent support. 

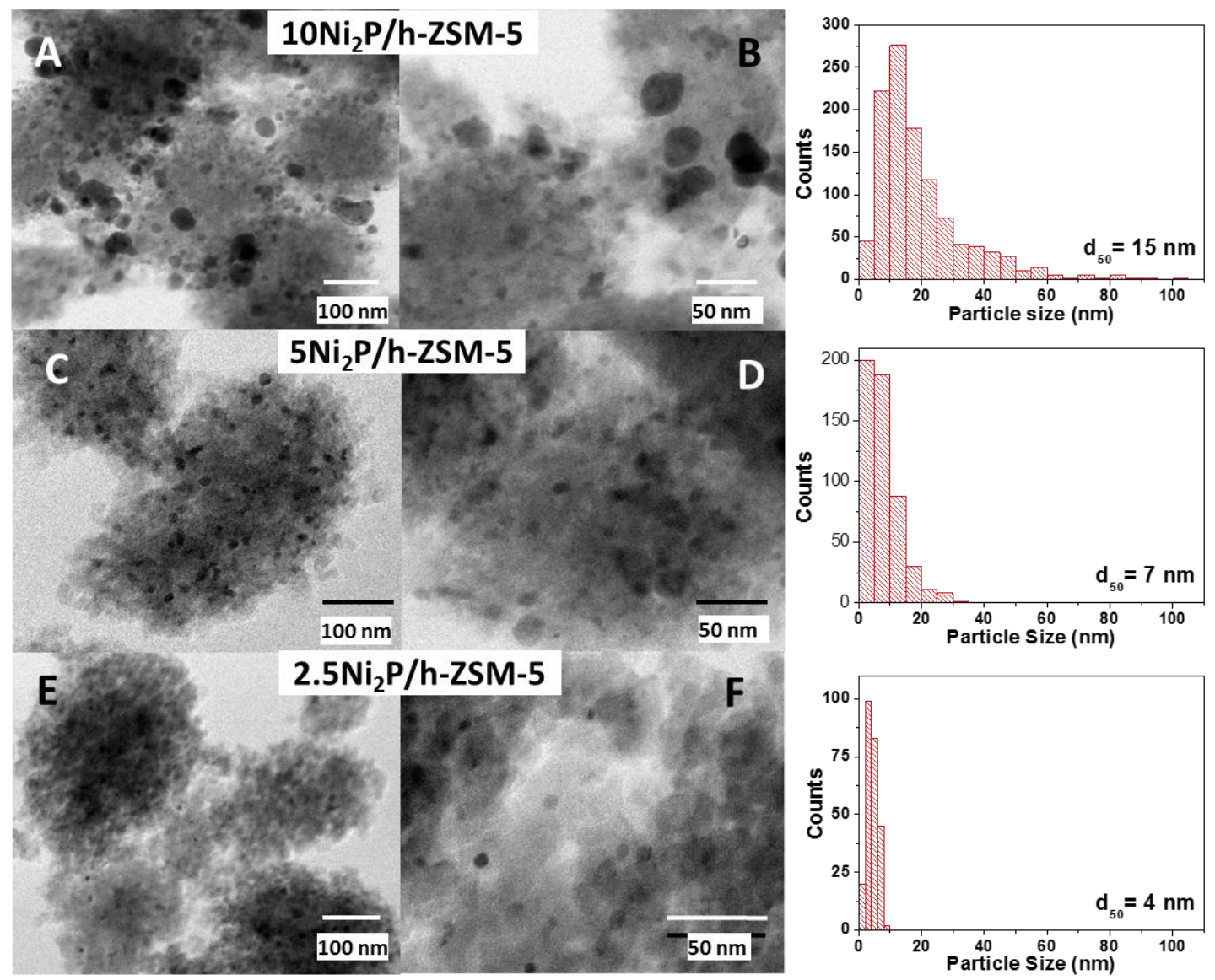

Fig. 2. (A-F) TEM micrographs of $\mathrm{Ni}_{2} \mathrm{P} / \mathrm{h}-\mathrm{ZSM}-5$ and corresponding $\mathrm{Ni}_{2} \mathrm{P}$ particle size distributions. 

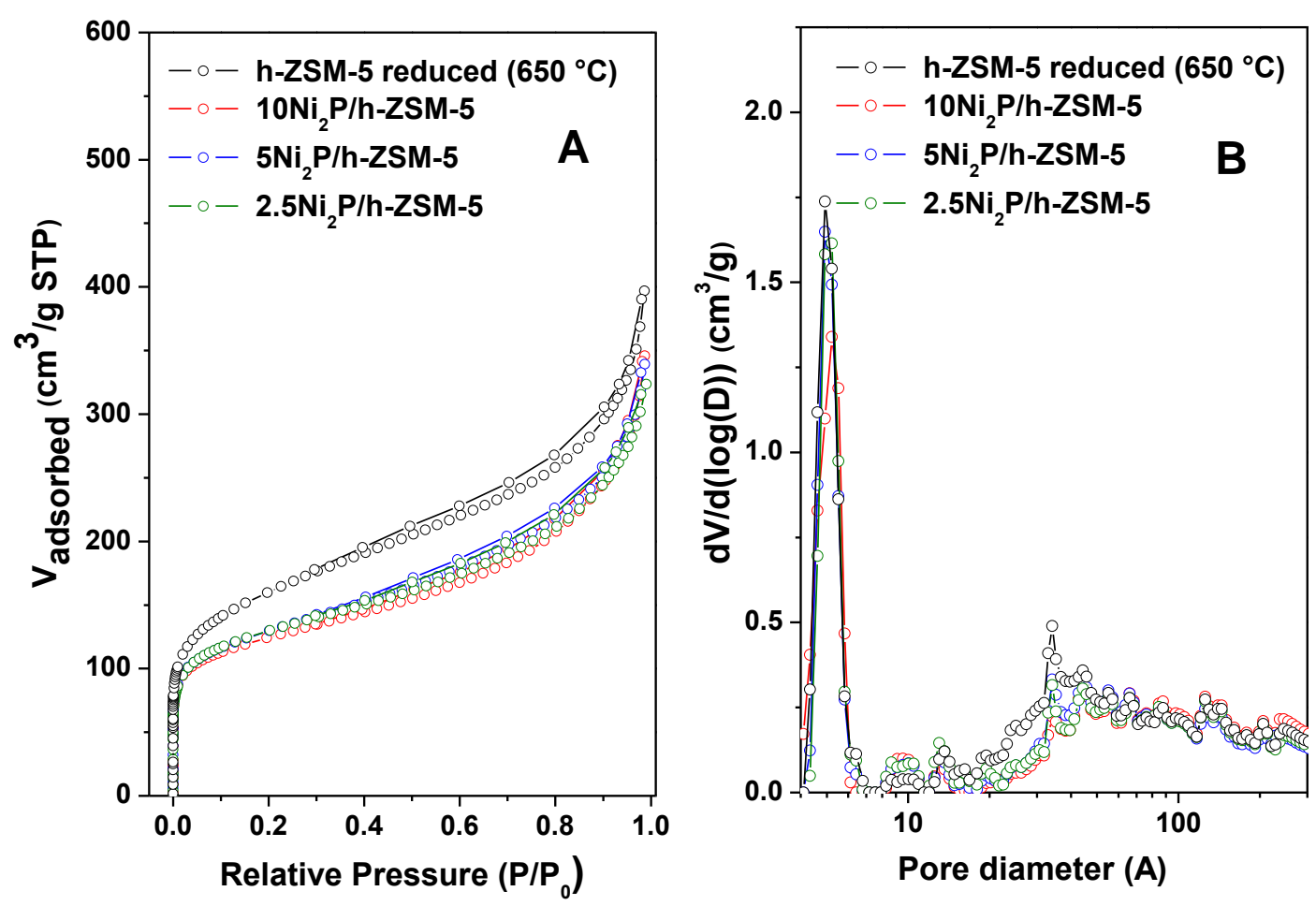

Fig. 3. (A) Ar adsorption-desorption isotherms at $87 \mathrm{~K}$, and (B) pore size distribution estimated from NL-DFT model of $\mathrm{Ni}_{2} \mathrm{P} / \mathrm{h}-\mathrm{ZSM}-5$ and parent support. 


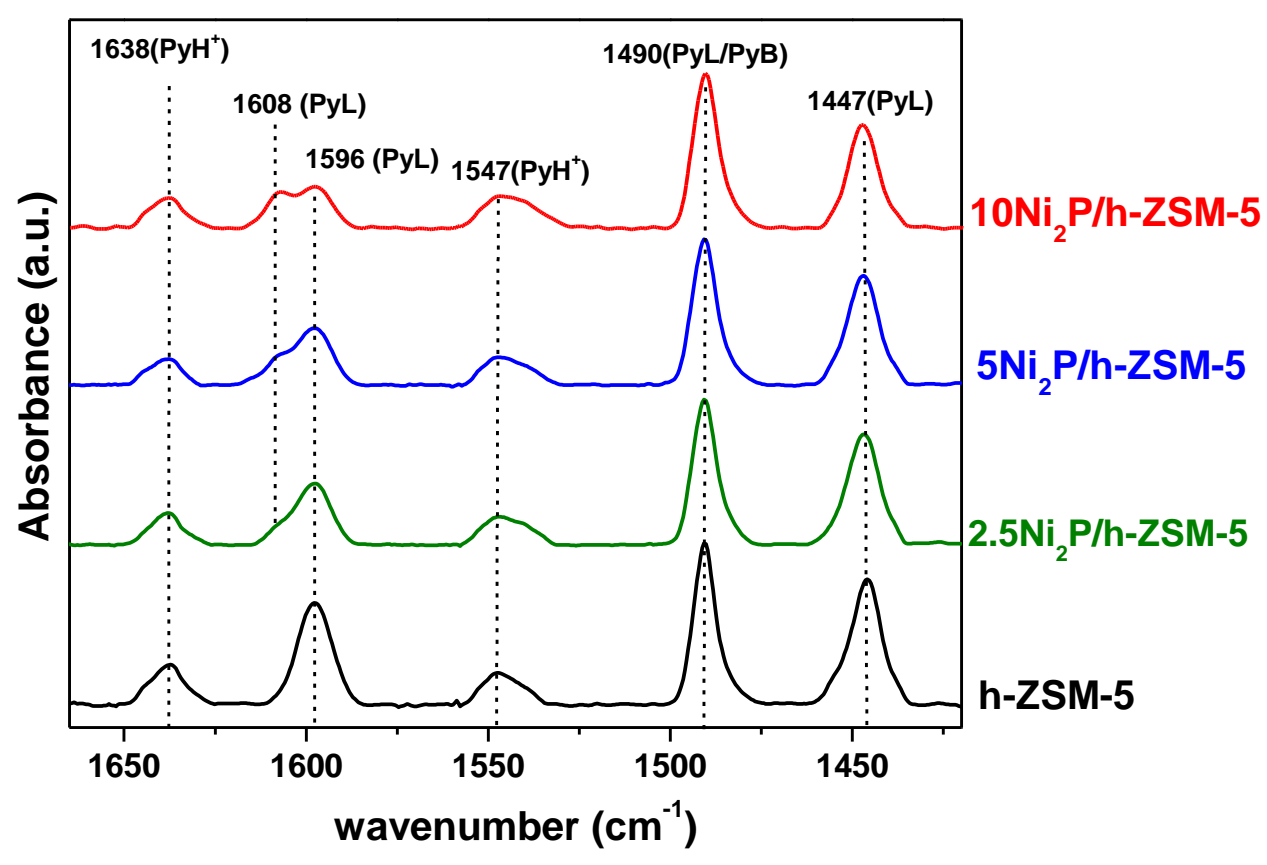

Fig. 4. DRIFT spectra of chemisorbed pyridine over $\mathrm{Ni}_{2} \mathrm{P} / \mathrm{h}-\mathrm{ZSM}-5$ and parent support. 

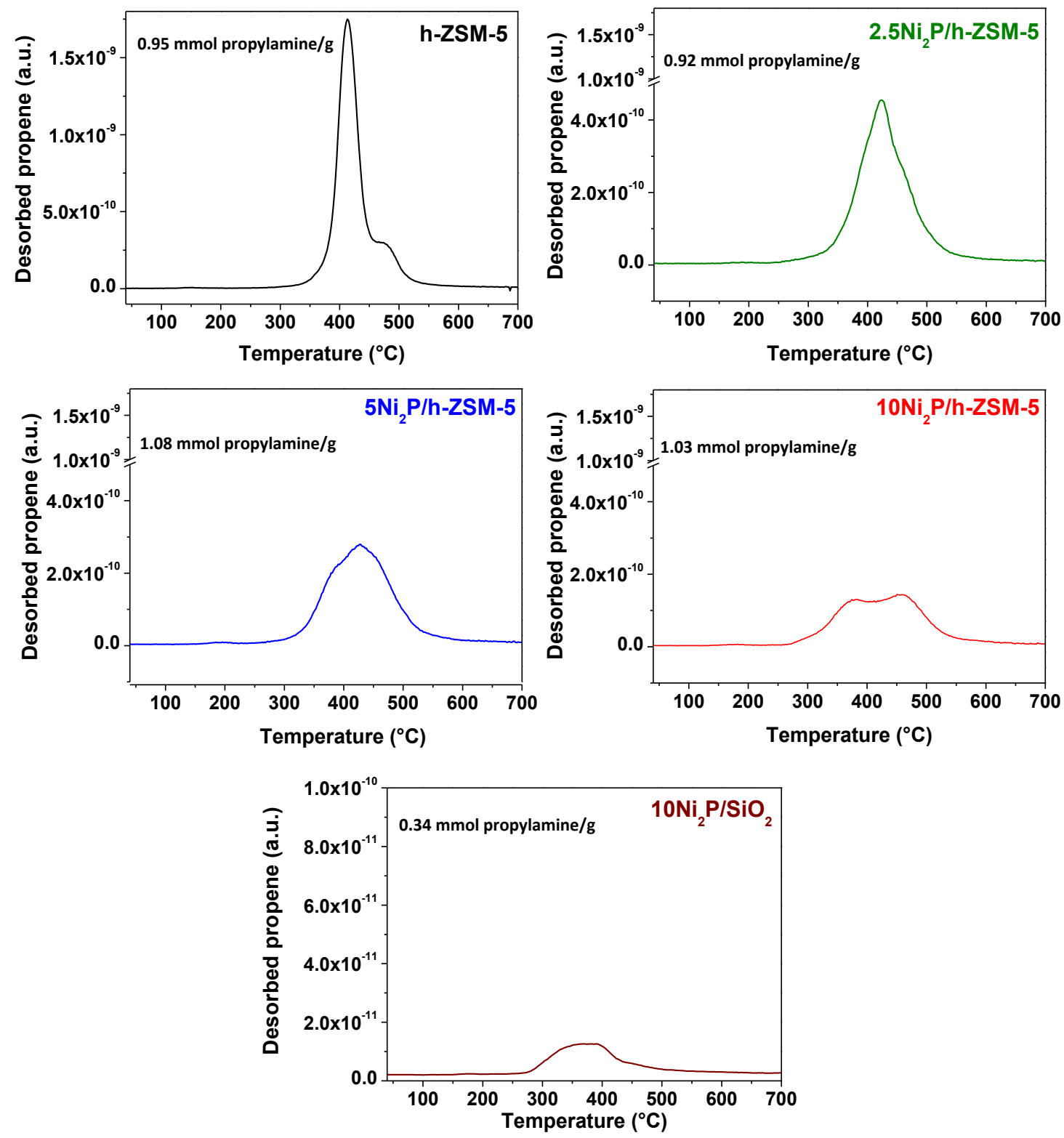

Fig 5. Temperature programmed desorption of reactively formed propene from propylamine decomposition over $\mathrm{Ni}_{2} \mathrm{P} / \mathrm{h}-\mathrm{ZSM}-5$ and $\mathrm{Ni}_{2} \mathrm{P} / \mathrm{SiO}_{2}$ reference. 


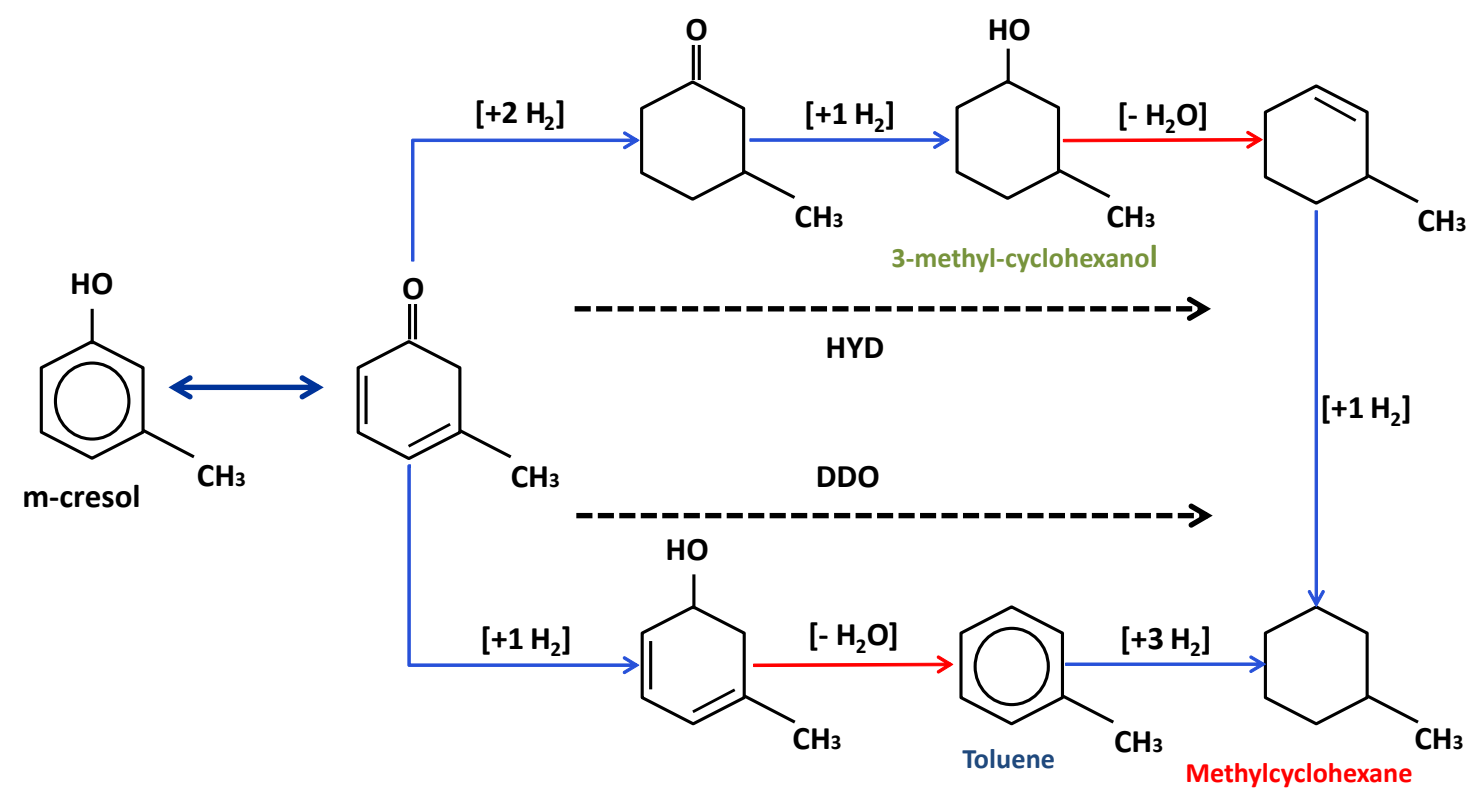

Fig. 6. Proposed reaction pathways in m-cresol hydrodeoxygenation. 

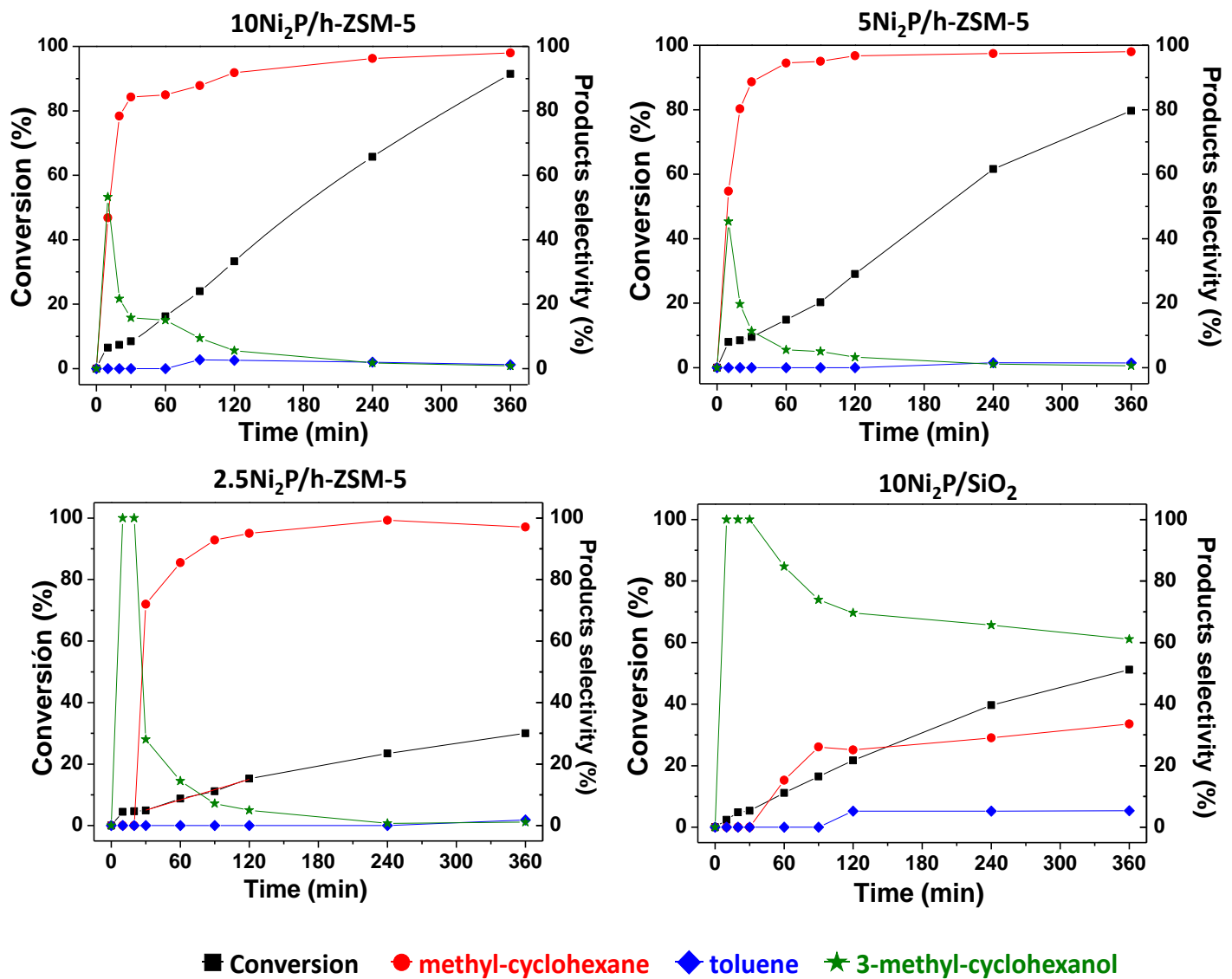

Fig. 7. $\mathrm{m}-\mathrm{Cresol}$ conversion and product distribution as a function of reaction time over $\mathrm{Ni} 2 \mathrm{P} / \mathrm{h}-\mathrm{ZSM}-5$ and $\mathrm{Ni}_{2} \mathrm{P} / \mathrm{SiO}_{2}$ catalysts. 


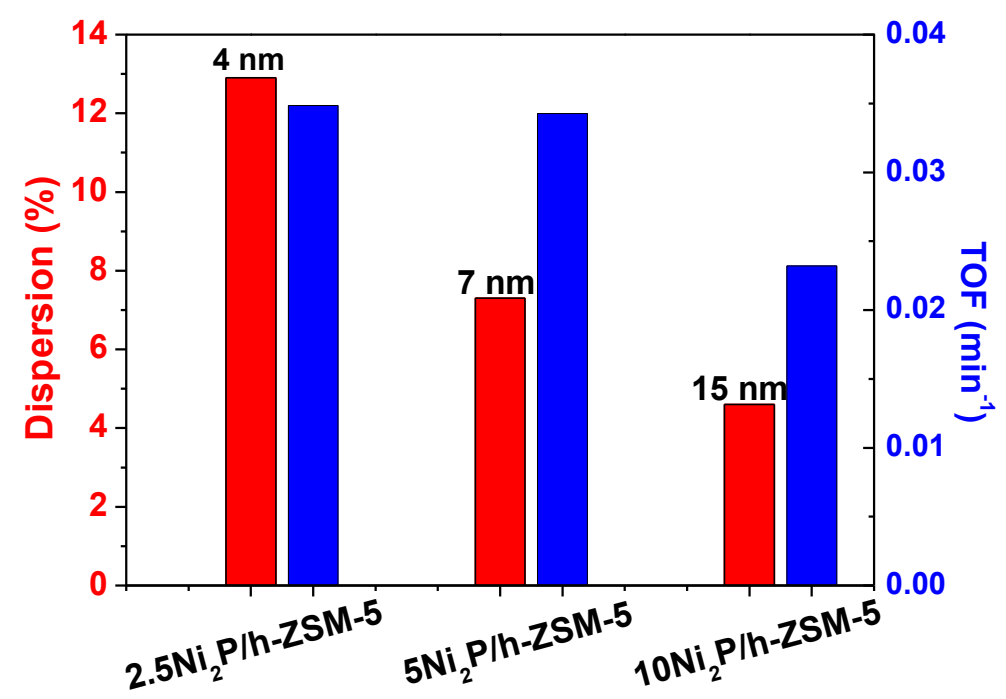

Fig. 8. Correlation between turnover frequency for $\mathrm{m}$-cresol $\mathrm{HDO}$ and active phase dispersion of $\mathrm{Ni}_{2} \mathrm{P} / \mathrm{h}$ ZSM-5 catalysts. 


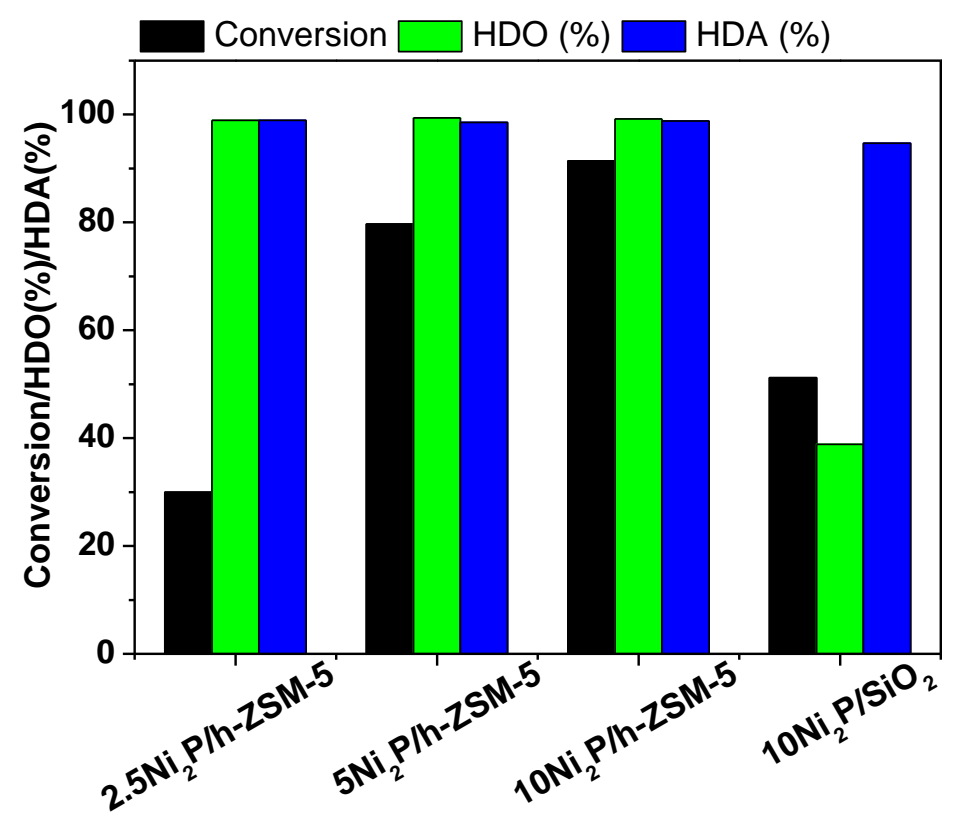

Fig. 9. m-Cresol conversion and hydrodeoxygenation (HDO) and hydrodearomatization (HDA) efficiencies over $\mathrm{Ni}_{2} \mathrm{P} / \mathrm{h}-\mathrm{ZSM}-5$ and $\mathrm{Ni}_{2} \mathrm{P} / \mathrm{SiO}_{2}$ catalysts. 


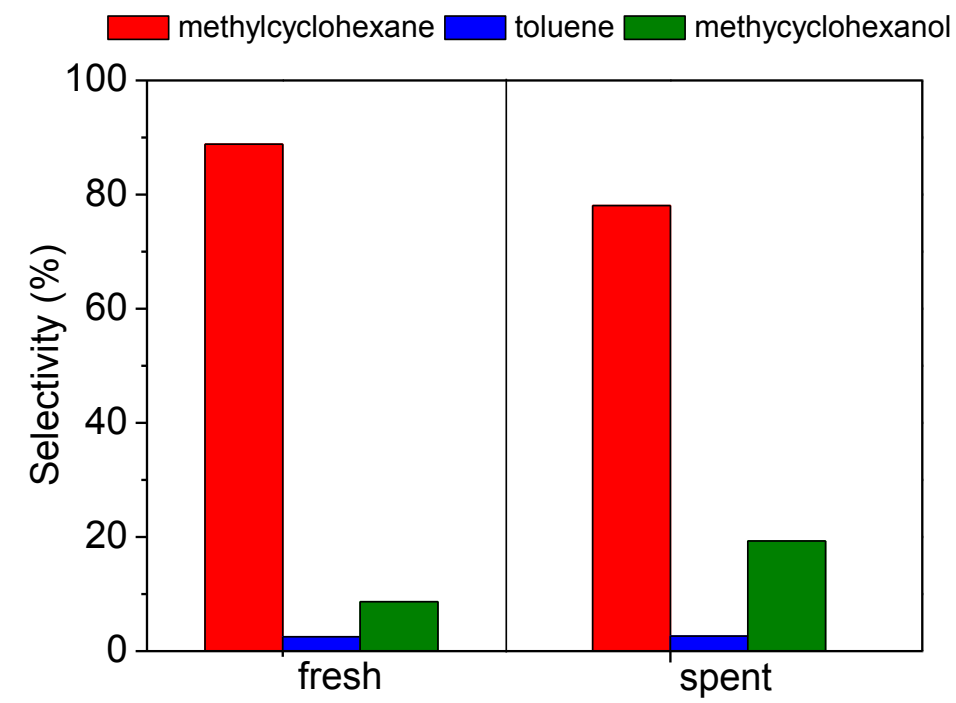

Fig. 10. Reutilization of $5 \mathrm{Ni}_{2} \mathrm{P} / \mathrm{h}-\mathrm{ZSM}-5$ catalyst: Products distribution. 